\title{
An Analysis of Historical Influences of Modern Chinese Overseas Students in Japan on Education Modernization in Zhili Province
}

\author{
Guofu Fan \\ College of Education, Hebei University, Baoding 071002, Hebei, China \\ $\&$ \\ The Central Institute for Correctional Police, Baoding 071000, Hebei, China \\ E-mail: fanguofu@163.com
}

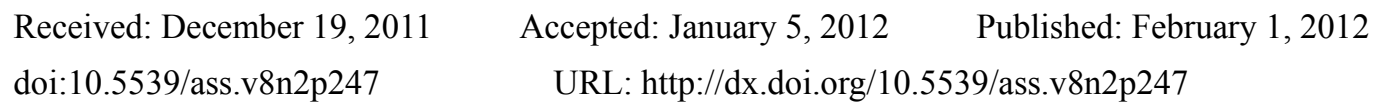

\begin{abstract}
This article made an analysis and demonstration of historical influences of modern Chinese overseas students in Japan on education modernization in Zhili Province with the aim of making up for disadvantages regional study in studies of modern Chinese education history, recognizing and evaluating in an impartial and justified way the historical position and influences of Chinese overseas students in Japan on modern Chinese education history and enriching the content and system of study on Chinese modern education history.
\end{abstract}

Keywords: Chinese overseas students in Japan, Zhili Province, Education modernization

A general survey of modern Chinese history, it is obvious and without doubt to all that the issue of studying abroad is important, influences of overseas students are profound and propelling of Chinese overseas students on modernization of Chinese education. Just as Shu Xincheng said, "In the contemporary China, the issue of studying abroad has almost become the foundation for all education issues or political issues. Although it is enough from the opinions of the speeches given recently to prove how this issue is important. Yet, given the fact that domestic political and educational undertakings are all, without exception, supported and affected directly or indirectly by Chinese overseas students in abroad, it is more obvious to see the significance of the issue of studying abroad." (Shu Xincheng, 1928).

Dispatch of Chinese overseas students in Japan that was originated in 1896 and the upsurge of studying in Japan that was launched on a grand and spectacular scale afterwards were movements of studying abroad with rare scale in the history of modern Chinese studying abroad. "In a certain sense, during the historical process from the New Deal that was launched by Kang Youwei and Liang Qichao in the Twenty-fourth Year of Guangxu (1898) until establishment of New China, there has almost had no incident that has not had any relation with Chinese overseas students in Japan and that has not been affected by Chinese overseas students in Japan." (Wang Xiangrong, 2000) After the large number of Chinese overseas students in Japan came back to China in succession, they, one after another, entered the political circle and education circle of China and had made indelible contributions to construction of education modernization in Zhili Province and development of modern Chinese education. Specifically speaking, Chinese overseas students in Japan mainly have the following three influences.

\section{Chinese overseas students in Japan are the important propelling factor for education modernization in Zhili Province}

According to the statistics, it was general that the number of Chinese overseas students in Japan accounted for $70-90 \%$ of the total Chinese overseas students abroad across the whole country before the year 1928, which was obviously more than the number of overseas students in Europe and America at the same stage. It could be said without any exaggeration that, "Chinese politics after the Hundred Day's has had something to do with Chinese overseas students in Japan all the time, especially in the fields of military, diplomacy and education. Almost seven or eight out of ten armymen who command the army troops now graduate from Japanese army schools and we can find their names from the list of Tokyo Shimbu Gakkou (the Thirty-third year of Guangxu)... Other fields, such as, diplomacy, was almost totally under control of Chinese overseas students in Japan. And more 
than nine out of ten persons in the higher education field (according to the class book of Southeast University and Beijing Normal University in the Republic of China) are Chinese overseas students in Japan. Almost all important undertakings across the whole country have Chinese overseas students who study in Japan" (Shu Xincheng).

In 1907, the Qing Government stipulated that, for all those who studied abroad with official financial support, when they came back to China, they had to hold the position of a special teachers for five years to fulfill their obligations. And before their obligation course was met, they should not be arranged for other appointment. This enabled a large majority of Chinese overseas students in Japan to have to, first of all, undertake education whatever major they had been learning. As a result, there appeared a group of Chinese overseas students studying in Japan with an extremely considerable number and extremely extensive distribution in all sorts of schools at all levels across the whole country. A large majority of Chinese overseas students studying in Japan were involved in education after they came back to China, which further enriched the teachers' quality in all sorts of schools at all levels and expanded the team of teachers. They had translated a lot of western books with Japanese and partly transferred Japanese education into China, which widely spread the idea of modern education.

"Owing to the geopolitical relations and the fact that Beijing is the center of politics, quite a large number of Northern Chinese overseas students studying in Japan were distributed in all cities of the country. And there were also Chinese overseas students studying in Japan with a native place of Jiangnan also sought for an occupation in such developed cities as Peiping and Tianjin, Baoding and so on in Zhili Province. There were also a lot of people going deep into small towns and rural areas to undertake grass-root work." (Jiang Pei, 2005) Then, quite a large number of Chinese overseas students studying in Japan were allocated to all sorts and all levels of educational institutes in Zhili Province after they came back to the country and become an important propelling factor for modernization of education in Zhili Province. Furthermore, in the nature of things, Zhili Province became one of the regions that earlier transmitted and received modern education concepts and conducted modern education reform among all provinces in the later period of Qing Dynasty, and had strong demonstrative feature all over the country. For a moment, all sorts of education in Zhili Province was developed rapidly, especially military education, political and legal education and normal education, when was the most rapid developmental stage throughout the history. "Training of high-ranking officers, the system of policeman, reformation of judicature and popularization of education all originated from Zhili Province and either the central government or all other provinces just followed suit." (Xu Zhili, 1966)

In terms of military education, as the first province in China that conducted naval and land forces reform the earliest, Zhili Province had no rival and was second to none considering its perfect military education system, its large military scale and its profound influences on modern Chinese military field. Under influences and with participation of Chinese overseas students studying in Japan who came back to China, Zhili Province set up a relatively perfect horizontal and longitudinal military education system. For example, among all the presidents of Baoding land military academy that was initially set up in 1910 and was stopped in 1923, except for the first, fourth and seventh presidents, all other presidents were Chinese overseas students who had studied in Japan, including Jiang Fangzhen, Qu Tongfeng, Yang Zude, Jia Deyao and so on. The chiefs of education, artilleryman, infantryman and avalryman all graduated from Japanese military schools.

In terms of legal and political education, the new legal and political education in China started in Zhili Province. However, the legal and political schools in Zhili Province at the end of Qing Dynasty and at the beginning of the Republic of China were almost under control of Chinese overseas students who majored in law and politics in Japan. These people cultivated a lot of legal and political talents who are in urgent need by China in a transitional period according to Japanese legal and political education model, Japanese teaching material, educational method and legal terms as well as legal system. For example, Zhili Nie Shu Legal and Political School (Zhili Legal School) was the first special legal school in China and its school regulation, teaching management, curriculum setting and method almost duplicated Japan, becoming the example for all other provinces to open legal and political schools later. Furthermore, Beiyang Legal and Political School was initiated and made preparations by Li Yuan and Ji Jing who were Chinese overseas students who studied in Japan. And four out of the six supervisors were overseas students studying in Japan who were respectively the first supervisor Li Yuan (graduating from the legal department in Chuo University of Japan), the second supervisor Xiong Fanyu (graduating from Japanese Waseda University), the fifth supervisor Li Ju (graduating from Japan Thammasat University) the sixth supervisor Hu Yuanjiang (graduating from Japanese Waseda University). Besides, the chief of educational administration Ji Zhongyin was also an overseas student who had studied in Japan. After the Republic of China was founded, the judicial system of the central government took the judicial 
system in Zhili Province as the example.

In terms of normal education, most of Chinese overseas students studying in Japan who were dispatched by Zhili Province were majored in teacher training and those overseas students who returned to country had made great contributions to normal education in Zhili Province. Affected by Chinese overseas students studying in Japan, both the quantity and quality of normal schools that were initiated in Zhili Province ranked top across the country. According to statistics, the number of normal schools in Zhili Province in 1908 was 54, which accounted for $9 \%$ of the total number of normal schools at that year all over the country, second only to Shandong Province and ranking the second in the whole country. The number of students in normal schools was 5370 , which accounted for $15 \%$ of the total number of normal school students at that year and 3.16 times more than the number of students in Shandong Province, ranking the first in the whole country. (Note 1) Furthermore, most rules and regulations of the normal schools were formulated by Chinese overseas students studying in Japan who borrowed the same category of school rules and regulations in Japan and most courses referred to the Japanese curriculum system. For example, the curriculum setting of Zhili Normal School in which the overseas students in Japan Jin Bangping held the position of discipline chief and Zhang Yingxu held the position of supervisor was almost similar to that in Tokyo Normal School. "There were altogether 16 courses in the four years of undergraduate in Tokyo Normal School and there were 14 courses in the curriculum schedule in the first classroom of Zhili Normal School. The exact same courses of the two schools were cultivation (ethics), education, geography, history, physics, chemistry, natural history, arithmetic, drawing, handwork, gymnastics and mandarin (grammar)". (Liu, Hong, 2004) "Since education in our country was still at its childhood age, it was hardly able to look truly into the truth of the world. We would rather choose literal translation of foreign works than an arbitrary decision and discussion for our people to use it, so as not to affect adversely our later generation.". (Chen Hongxiang, 1991) Zhili's selection of teaching materials in normal education was almost translated from Japanese and it ranked the first across the country. Just as Yuan Shikai said in his memorial to the throne in 1902 to set up Zhili Normal School, "We can first of all translate all western common books into Japanese and then translate Japanese into Chinese. Then, our people can thoroughly understand and are likely to achieve any achievement."(Memorial by Yuan Shikai, 1987) Among all provinces across the country, Zhili Province was the only province that compiled and translated teaching materials by itself and was approved by the division of education to issue its teaching materials to all other provinces. Considering the works about translation and normal education theory, "The Education Magazine" (renamed as "Zhili Education Magazine" in 1907) that was initiated by Zhili Student Affairs Office serialized in 1905 "Teaching Materials" that was lectured by Bo Duo Ye Zhen Zhi Zhu and edited by Zhili overseas students studying in Japan, serialized in 1906 and 1907 "Education Theory Popular to Family and School" that was translated by Deng Bianlian and Shi Nvshi, serialized in 1907 and 1908 "Women Normal Education" that was written by Zuo Kou Mei Dou Zi and translated by Ai Chen and published in 1911 "Actual Education Theory" that was written by Liu Zheng Tai Lang and translated by Ai Chen. All these works and publications were one of the critical factors for education in Zhili Province to rank the top in the whole country at the end of Qing Dynasty and at the beginning of the Republic of China.

\section{Modern education reform in Zhili Province occupied a leading position across the country which had} typical representativeness

The particular geographical position of Zhili Province neighboring the capital city determined its particular political and historical position. "For the last one decade, the great project of national modernization and operation was mostly initiated in Zhili and then gradually spread to all other provinces. Although Zhili was only one corner of the country, it was the key to flourishing and abolishing of the country." There was a magnificent antithetical couplet in the front of the governor office in Zhili, which said, "swallowing the desert in the north, stretching the Yellow River in the south, multiple rivers flowing together in the middle, ruling the northern part of the country, with Taihang Mountain in the west and Bohai in the east as the protective screen. It internally conducted official management and externally learned western military technique, holding the position of trade relations in Tianjin, Yingkou and Yantai. There was a generation of well-known ministers, with Zeng Guofan as the teawcher and Li Hongzhang as the student." The antithetical couplet fully proved that point.

The particular political and historical position of Zhili Province decided that it took up a leading position in the modern Chinese education reform whether in terms of scale, quantity and influence or in terms of structure and level. It became a source for the central government to collect experiences and the target for all other provinces to struggle to simulate and had typical representativeness. Just as the American churchman D. W. Zyon said in his report to American and Canadian youth alliance organization "North America Association", "Beijing is the center of former education and Tianjin can be regarded as the center for Chinese government to start western 
education. Tianjin has already had a medical school, a navy school, a telegram school that is unique across the whole country and Beijing School that has been fully grown at its embryo age." (Note 2) The specific practice is as follows:

Zhili formulated such ten school regulations as "Experimental Regulation of Beiyang Royal Camp to Initiate a School" and "Experimental Regulation of Zhili Legal and Political School" and promulgated and implemented these ten school regulations. Besides, these ten school regulations were all ranked the top among the school regulations of the same category in the country. "Needless to say military school regulations, even the three school regulations of normal university, junior and senior middle school and primary school were slightly earlier than the regulations of the same category promulgated by Qing Government. Regulations of legal and political schools and military schools were also pioneering all over the country." (Wang Jinxia, 2006)

\subsection{Educational rules in Zhili Province ranked the top in the whole country}

Yuan Shikai had made great contributions to construction of educational rules in Zhili Province at the end of Qing Dynasty. After Yuan Shikai took up the position of governor-general in Zhili Province in November 1901, he set about formulating all sorts of school regulations. Within the short period of four years from June 1902 to July 1906, Yuan Shikai had formulated ten school regulations, including “

\subsection{Zhili Province was one of the areas that conducted earlier educational administration reform}

Rapid development of all sort of new schools in Zhili Province encouraged the provincial capital of Zhili and all $\mathrm{Fu}$, Ting, Zhou and Xian to set up numerous and complicated schools one after another. These schools had to have one person to supervise the school discipline so as to achieve regularity and thoroughness, systematic and orderly." (Liao Yizhong \& Luo Zhenrong, 1987) In order to strengthen management of all sorts of new schools, Zhili Province took the lead in setting up an administrative organ --- school department --- to take charge of the national education affairs on a nation wide scale in 1902 under support of Yuan Shikai. This school department invited Du Bian Long Sheng, the president of Tokyo Music School and professor in Tokyo Higher Normal School, to hold the position of education consultant in the school department of Zhili Province. The school department in Zhili was the earliest provincial education administrative organ at that time in China, which was three years earlier than the first class division of education of the central government and almost two years earlier than the student affairs office in other provinces. In July 1904, according to the "School Affairs Outline" that was promulgated and implemented by the Qing Government, Zhili Province changed the School Department in Zhili into Zhili school affairs office. "The school affairs office is in charge of school affairs and is under jurisdiction of the governor-general. For the first time, the position of Duban was set up and was selected by the governor-general. Below the Duban, one member for Canyi, one member for the special education office, one member for the general education office and one member for compilation and translation office were all selected by the governor-general and were under jurisdiction of the governor-general. Official documents for Canyi, routine documents for the executive office, the two offices for the special education and all inspections by the executive office were assessed and determined by the governor-general who was invited to assign. Ecclesiarch and the one who was in charge of writing were all evaluated by the governor-general." (Zhu Youhuan, Qi Mingxiu, Qian Manqian \& et al, 1993) In May 1906, in response to the requirement of the division of education, Zhili Province changed school affairs office into Ti Xue Shi Si (name of government official title). "Xue Shi was in charge of education in the whole province and had authority over education in the whole province. The position of Xue Shi was quite important and prominent." (Ta Kung Pao, 1906) At the time when Zhili Province set up provincial education administrative management institutes, such grass-root education administrative management institutes in Fu Zhou and Xian were also set up. The system of encouraging learning that was carried out in education administrative management in $\mathrm{Fu}$, Zhou and Xian at the end of Qing Dynasty was also started earliest in Zhili Province. After positive implementation, the system of encouraging learning was proved to be highly effective. "In the year 1909, the number of primary schools in Zhili Province ranked the first among all provinces in the whole country and the number of primary school students ranked the second. Both the number of middle schools and the number of middle school students ranked the third in the whole country. Both the number of higher schools and the number of higher school students ranked the first in the whole country. The number of primary school teachers who graduated from normal schools and who were foreign teachers ranked the first in the whole country. The number of middle school teachers who graduated from normal schools and who were foreign teachers ranked the second in the whole country. The number of higher school teachers who graduated from higher schools at home and abroad ranked the first in the whole country. The number of schools for encouraging learning and the members of schools for encouraging learning ranked the first in the whole country." (Chen Qitian, 1979) In 1909, the whole province "set up 152 schools for encouraging learning, which had 153 members and 713 students, ranking the first in the whole country. By that time, a flourishing atmosphere 
had appeared in Zhili that emphasized on education." (Jiang Pei, 2005) After the Republic of China was founded, all sort of education in Zhili Province still kept a strong and vigorous development trend and continued to rank the top position in the whole country.

\subsection{The number of new schools and the number of students ranked the top all over the country}

Zhili Province has laid foundation for a variety of education in construction of new types of schools and became the birth place of almost ten sorts of schools in China. "According to statistics by the division of education, by the $33^{\text {rd }}$ year of Guangxu (1907), there had already been 12 special schools in Zhili Province, 20 industrial schools, 3 advanced normal schools, 90 elementary normal schools, 5 education centers, 30 middle schools, 7391 primary schools, 121 female schools and 2 preschool education schools, altogether 8723 schools, ranking the first place in the country. The number of students was 164,000 , ranking the second place in the country. The total assets for school affairs was 4.8 million Liang, ranking the first place in the country." (Shen Yunlong, 1986) "In 1909, there were algether 11201 schools and education locations in the whole province of Zhili, ranking the first place in the country." (Jiang Pei, 2005)

3. Historical position and influences of Chinese overseas students studying in Japan in the process of modernization of education in China

Considering the current studies, the important role of Chinese overseas students studying in Japan in the process of Chinese education modernization was beyond all doubt. Especially during the period before the "May $4^{\text {th }}$ Movement", development of Chinese modern education was mainly to follow the example of Japanese education through Chinese overseas students studying in Japan. The specific examples were as below:

(1) Affected by Chinese overseas students studying in Japan, the country formulated modern schooling system that imitated Japan in "Prescriptive School Regulations" and "Approved School Regulations".

(2) The country vigorously advocated the education goal of national military education.

(3) The country formulated "Interim Procedures for General Education" and "Gui Chou School System" at the beginning of the Republic of China.

(4) The country brought in Japanese curriculum system affected by Chinese overseas students studying in Japan.

(5) Affected by Chinese overseas students studying in Japan, the country translated and brought in Japanese textbooks and educational theory works, which promoted formation of the modern Chinese education and propelled dissemination and development of modern education theory.

To sum it up, study on the subject of "Modern Chinese overseas students studying in Japan and modernization of education in Zhili" and retrospect and reflection on the influences of Chinese overseas students studying in Japan on modernization of education in Zhili Province help to make up for disadvantages in regional study in the research of modern Chinese education history, recognize and evaluate the historical position and influences of Chinese overseas students studying in Japan on modern Chinese education history in an objective and justified way and enrich content and system of modern Chinese education history study, which has great theoretical value and realistic significance.

\section{References}

(1906). Discussion on the Position of Ti Xue Shi. Ta Kung Pao, May 28.

(1987). Memorial by Yuan Shikai (Vol. 2). Tianjin: Tianjin Ancient Books Publishing House, 581.

Chen, Hongxiang. (1991). Chronicle of Wang Guowei. Jinan: Qilu Press, 65.

Chen, Qitian. (1979). Modern Chinese Education History. Beijing: Zhonghua Book Company, 159.

Jiang, Pei. (2005). On the Historical Role of the Overseas Chinese Students, the Government Officials and Gentry Observing in Japan in the Course of Modernization in Zhili Province(1900-1928). Journal of Historical Science, (5).

Jiang, Pei. (2005). On the Historical Role of the Overseas Chinese Students, the Government Officials and Gentry Observing in Japan in the Course of Modernization in Zhili Province(1900-1928). Journal of Historical Science, (5).

Jiang, Pei. (2005). On the Historical Role of the Overseas Chinese Students, the Government Officials and Gentry Observing in Japan in the Course of Modernization in Zhili Province(1900-1928). Journal of Historical Science, (5).

Liao, Yizhong \& Luo, Zhenrong. (1987). Memorial of Yuan Shikai (Vol. 2). Tianjin: Tianjin Ancient Books 
Publishing House, 598

Liu, Hong. (2004). Japanese Effects on Education Reform in Modern China. Journal of Hebei University (Philosophy and Social Science), (2).

Shen, Yunlong. (1986). Collection of Modern Chinese Historical Data, Vol. 3 (10th Version, 93rd Volume). Taipei: Wenhai Publishing House, 35-36, 27-28.

Shu, Xincheng. (1928). History of Modern Chinese Studying Abroad. Zhonghua Book Company, 1.

Wang, Jinxia. (2006). Hebei and Earlier Chinese Education Moderinzation. Baoding: Phd thesis of Hebei University, 54.

Wang, Xiangrong. (2000). Study in Japan. China Youth Publishing Group, 206.

Xu, Zhili. (1966). Yang Shou Yuan Zou Yi Ji Yao Ba, edited by Shen, Zuxian. Taipei: Wenhai Publishing House.

Zhu, Youhuan, Qi, Mingxiu, Qian Manqian \& et al. (1993). Compilation of Data about Modern Chinese Education History --- Education Administrative Institute and Education Group. Shanghai: Shanghai Educational Publishing House, 32-33.

\section{Notes}

Note 1. Shen, Yunlong. (1983). The First Educational Statistical Chart, in the $10^{\text {th }}$ Version of "Collection of Modern Chinese Historical Data (Vol. 3). Taipei: Wenhai Publishing House. See Wang, Jinxia. (2006). Hebei and Earlier Chinese Education Moderinzation. Baoding: Phd thesis of Hebei University, 16.

Note 2. Zhou, Zhihua \& Zhong, Yi. (1994). Chronicle of Events in Education in Hebei. Shijiazhuang: Hebei People's Publishing House, 10. "Beiyang School" that was mentioned in the letter was not wrong. In 1895, Sheng Xuanhuai initiated Tianjin Chinese and Western School and the first class in that school was afterwards named as "Beiyang School." In 1900, this school was destroyed in National Upheaval of Gengzi. In 1903, this school was recovered and was formally named as Beiyang School. 